\title{
IMPLICACIONES POLITICAS DE LA PREDESTINACIÓN AL COMIENZO Y AL FINAL DE LA EDAD MEDIA: JUAN ESCOTO ERIGENA Y JOHN WYCLIF
}

Francisco Bertelloni*

SIINTESE - O tema da predestinação dos homens, uns, para a salvação eterna, outros, para a condenação, constitui, aparentemente, apenas uma questão teológica. Examinando com maior profundidade dois casos em que este tema foi causa de polêmicas, dentro do mundo cristão, percebese que, por trás das questões dogmáticas, havia um conteúdo político não manifesto que poderia abalar a ordem vigente.
ABSTRACT - The subject of the predestination of mankind, some to eternai salvation and others to eternal condemnation, seems to be only a theological problem. But, if we examine more profoundly two cases in which this theme has caused polemics in the Christian world, we see that behind the dogmatic questions there was an hidden political content, which could shake the established order.

\section{1 - Juan Escoto Erígena y el problema de la predestinación}

En el capitulo II del tratado De divina praedestinatione, escrito entre fines de 850 y principios de 851, Escoto Erígena identifica a un cierto Godescalco, que habría sostenido dos predestinaciones divinas, una a la salvación, otra a la eterna condena:

¿¿Dónde están, Godescalco, las necesidades de tus dos predestinaciones? De tus predestinaciones, digo, no de las de Dios. Tu perversidad las inventó, y por ello no existen....".

Escoto escribió el De praedestinatione por encargo de las autoridades eclesiásticas de la parte occidental del Imperio para refutar el pensamiento de Godescalco sobre la existencia de dos predestinaciones. De los argumentos de Escoto, tres son especialmente interesantes. Podemos denominarlos así: (1) preciencia es género y

Universidad Nacional de Buenos Aires.

1 Cfr. Migne, Patrologia Latina, tomo 122, col. 360.

\begin{tabular}{|l|l|l|l|l|l|}
\hline VERITAS & Porto Alegre & v. 41 & $\mathrm{n}^{0} 163$ & Setembro 1996 & p. 391-409 \\
\hline
\end{tabular}


predestinación es especie; (2) en Dios no hay tiempo; (2) dos efectos lógicamente contradictorios no pueden ser retrotraídos a la misma causa.

El primer argumento ${ }^{2}$ está articulado en torno de la relación lógica entre los conceptos de preciencia y predestinación divina. Objetivo del argumento es mostrar que el concepto de preciencia no es equivalente o convertible con el de predestinación. La predestinación presupone la preciencia, pues, antes de predestinar, Dios sabe lo que predestina. Para que haya predestinación es necesario que haya preciencia. El concepto de preciencia es anterior y más extensional que el de predestinación, del mismo modo como el concepto de virtud es anterior al de prudencia. La relación lógica entre preciencia y predestinación es equivalente a la relación lógica entre género y especie. La predestinación es una especie del género preciencia, pero no la única especificación posible: todo lo que cae bajo la especie predestinación cae automáticamente bajo el género preciencia, pero esa relación no es reversible, pues no todo lo que cae bajo el género preciencia se especifica como predestinación. Sucede lo mismo que entre el género animal y la especie hombre. Del mismo modo como no puede decirse que todo lo que pertenece al género animal se especifique como hombre, tampoco puede decirse que toda preciencia se especifique como predestinación. En toda predestinación hay preciencia, pero no en toda preciencia hay predestinación. El hecho de que Dios preconozca a los buenos y a los malos no implica que necesariamente los predestine al bien o al mal. Del hecho de que Dios preconozca todos los actos no significa que predestine todos los actos, pues Dios no puede predestinar lo que no es: en rigor en Dios solo hay predestinación "según la sustancia", y la única sustancia es el bien, no el mal que solo es ser relativo, relativamente al bien. Por ello solo hay una predestinación.

En el segundo argumento ${ }^{3}$ Escoto afirma que es engañoso hablar de pre-destinación o de pre-ciencia en Dios, pues Dios no existe en el tiempo sino en la eternidad; por ello su conocimiento carece de antes y de después. La prioridad de la

2 "Puesto que toda predestinación es preciencia, sin embargo notoda preciencia es predestinación; del mismo modo, toda prudencia es virtud, pero no toda virtud es prudencia... La razón divina está unida al eterno intelecto de modo tal que en él ve el ser de todas las naturalezas creadas por Él... y en él ve no solo los bienes que Dios habría de crear en su creación, sino tambien todos los males que hace la creatura racional utilizando con movimiento perverso el libre albedrio... Ese preconocimiento de todos los bienes de Dios y de todos los males de la perversa creatura puede ser llamado preciencia divina. Por ello puede decirse que Dios preconoce los buenos y los malos, si es que los males pueden ser preconocidos, lo que, en rigor, es solo un modo de hablar (modus locutionis). Ese mismo conocimiento es llamado predestinación, operación que se lleva a cabo tanto en los que se condenarán como en aquellos a quienes la gracia de Dios preparó la vida eterna.... pero en rigor hay en Dios solo predestinación según la sustancia, no relative [a la sustancia]...Por ello, la divina predestinación es solo una, no dos..." (cfr. ibid. col. 361-364).

"Debe saberse que la preciencia y la predestinación no pueden predicarse propiamente de Dios. Pues ¿cómo puede Dios preconocer algo con preciencia o predestinar con predestinación cuando para Él no hay futuro, ya que Él nada espera, y cuando para Él no hay pasado, ya que para Él nada transcurre? Pues asi como en Él no hay espacios de lugar, asi tampoco hay en Él intervalos de tiempo... En consecuencia, de qué modo se le puede atribuir preciencia, cuando para Ėl no hay futuro? Del mismo modo como no se puede decir que Dios tenga memoria, ya que carece de pasado, asi tampoco se puede decir que tenga preciencia, pues carece de futuro... Y sin embargo Dios vio, previo, conoció y preconoció todo lo que sucederia antes de que sucediera y vio y conoció eso mismo después que sucediera, porque, puesto que Él mismo siempre es eterno, asi la totalidad de lo que hizo siempre es etema en Él" (ibid., col. 392). 
ciencia y de la determinación divinas respecto de la creación no es una prioridad temporal, porque Dios no está en el tiempo, sino en la eternidad, y desde ella precede lógicamente a su creación sujeta al tiempo. Aunque hablamos de los actos divinos con categorías humanas, existe una inadecuación entre el eterno presente de Dios y nuestra temporalidad sujeta a la sucesión de pasado, presente y futuro. ¿Cómo se explica, por ejemplo, que en el tiempo tenga lugar la introducción de los medios de salvación antes que el juicio de réprobos, cuando en rigor, en Dios, ese juicio de réprobos es determinado como consecuencia del pecado de Adán, antes de determinar los medios de salvación? La única explicación es que existe una diferencia cualitativa entre la dimensión de la eternidad divina, en la que todos los sucesos temporales tienen lugar como en un eterno presente, y la dimensión de la temporalidad humana, en la que los hechos deben tener lugar en una sucesión cronológica. Escoto construye su argumento sobre la base de elementos que ya había expuesto Boecio en el De consolatione philosophiae. Esos elementos derivan del análisis de la naturaleza divina. ${ }^{4}$ Para Escoto el problema de la predestinación tiene su origene nel problema del conocimiento divino de la realidad, es decir en la omniscientia, tal como lo plantea Boecio. Omniscientia es el conocimiento absoluto y total que Dios tiene de toda la realidad en su integridad. Cuando se habla de predeterminación divina, la omniscientia asume la figura de la pre-ciencia y es anterior a la predeterminación, pues lo que Dios quiere - i.e. la voluntad divina que se expresa en su predeterminación - lo quiere porque antes lo sabe con su scientia o conocimiento. Pero en Dios se da en forma simultánea todo lo que sabe y todo lo que quiere. Hay predeterminación de algo cuando se determina ese algo antes de que se realice. Dios conoce todo y quiere todo lo que conoce en un mismo instante atemporal y eterno. Dios no sabe ni conoce nada como futuro sino en su eterno presente. Cuando hablamos de preciencia y de predestinación estamos haciendo referencias desde nuestro modo de conocimiento. Preciencia y predestinación no

4 "...veamos ahora, en la medida en que ello sea posible, cuál es la condición de la esencia divina, para poder reconocer a través de ello cuál es su ciencia. Es juicio común de todos los seres provistos de razón que Dios es eterno. Consideremos pues qué es la eternidad. Ésta nos mostrará al mismo tiempo la naturaleza y la ciencia divina. La etemidad, pues, es la posesión simultánea y perfecta de una vida sin fin, cosa que se mostrará más claramente confrontándola con las realidades temporales. Todo lo que vive en el tiempo procede, en el presente, desde el pasado hacia el futuro, y no hay ninguna realidad temporal que pueda abarcar todo el espacio de la propia vida; mientras no logra aferrar aún lo que sucederá mañana, ya ha perdido lo que ha sucedido ayer; y así en la vida del hoy, vive solamente el instante móvil y fugaz... [En cambio] el ser que reúne y posee en sí simultáneamente la total plenitud de una vida sin fin y al cual no le falta nada del futuro y no se le escapa nada del pasado, sólo ese ser es llamado con razón el ser eterno; y es necesario que, siendo plenamente dueño de sí, esté siempre presente a sí mismo y tenga presente el infinito decurso del tiempo... Y puesto que cada facultad de juicio comprende segin su propia naturaleza las cosas que le están subsumidas, puesto que Dios se encuentra siempre en un estado de etema presencia, por ello tambien su ciencia, superando toda mutación temporal, permanece en la simplicidad de su propia presencia, y, abrazando todos los espacios infinitos del presente y del futuro, los contempla en su propio simple acto de conocimiento como si sucedieran todos precisamente en ese mismo momento. Así, si quieres evaluar correctamente la providencia divina con la cual Dios distingue todas las cosas, debes considerar que no se trata de una preciencia, por asi decir, del futuro, sino de ciencia de una presencia que nunca caduca, razón por la cual ser mejor llamada providencia que preciencia, pues ubicada bien distante de los seres más bajos, ve delante de si todas las cosas como desde la cima más excelsa de todas las cosas" (Boecio, De consolatione philosophiae, V, 6). 
pueden ser atribuídos a Dios como predicado genuino, pues ellas presuponen un intervalo de tiempo entre la visión y el evento. No habiendo tiempo en Dios, no hay intervalo entre lo que ve y lo que quiere y la realización de lo que ve y lo que quiere.

El tercer argumento ${ }^{5}$ rechaza la posibilidad de que dos efectos que se oponen lógicamente puedan tener una causa común. Ahora bien, dos actos de predestinación, uno de los cuales constriñe a la salvación y el otro a la condena, se oponen lógicamente entre sí. Luego no pueden provenir de Dios, porque en la medida en que Dios puede ser descripto, es conocido como siendo absolutamente uno y simple, carente de toda división; toda referencia a algún tipo de división en Dios, en su sustancia o en su modo de ser,es metafórica. ${ }^{6}$ A partir de esta base Juan argumenta que es equivocado afirmar que la predestinación de Dios es doble, pues tanto la predestinación como la preciencia de Dios son parte de su sustancia, y ésta es absolutamente unitaria y simple, ${ }^{7}$ y una tal sustancia no puede ser causa de efectos lógicamente contrarios.

\section{2 - El rival de Juan Escoto Erígena}

¿Quién era Godescalco, que doctrina sostuvo y porqué lo combatió Escoto Erigena? La historia del pensamiento medieval ha identificado a dos autores que sostuvieron doctrinas predestinacionistas con el objetivo de que ellas tuvieran consecuencias políticas: Godescalco de Orbais en la primera mitad del siglo IX y John Wyclif en la segunda mitad del siglo XIV. Independientemente de esa coincidencia circunstancial,que excede el contenido teórico de ambas doctrinas, su contexto histórico y sus objetivos son diferentes. No mencionaré aquí las razones de esas diferencias. Baste señalar que Godescalco vivió en un mundo aún heredero de la concepción unitaria ético-política imperial carolingia y que intentó defenderla con su teoria de la predestinación.

En una doctrina difundida entre el clero de su época, Godescalco ${ }^{8}$ vio un grave peligro para la supervivencia de esa concepción imperial: según esa doctrina, bas-

5 "Existe otro argumento llamado de los efectos a las causas por medio del cual se puede concluir que no hay dos predestinaciones en Dios.Su formulación es la siguiente: de las cosas que son contrarias entre sí, es necesario que sus causas tambien sean contrarias entre sí. Es imposible que una y la misma causa produzca efectos contrarios entre si. Y qué es contrario a la esencia sino el no ser... qué a la justicia sino el pecado? ...En consecuencia, si es manifiesto que todas estas cosas son contrarias entre si, de ello se sigue que sus causas son también contrarias. Efectos contrarios no pueden nacer ni de una causa ni de dos causas del mismo género. Si en consecuencia, como se afirma heréticamente, hay en Dios dos predestinaciones, de las cuales una de ellas compele a la felicidad eterna mienras la otra compele a la muerte, ello es contradictorio...." (Migne, Patrologia Latina, tomo 122, col. 366).

Ibid., col. 362 .

Ibid., col. 364.

8 Sobre el pensamiento de Godescalco y de Rhabano Mauro, véanse los excelentes artículos de Gangolf Schrimpf que en parte sigo en mi exposición: "Der Beitrag des Johannes Scottus Eriugena zum Prädestinationsstreit", en: Die Iren und Europa im frühen Mittelalter (ed. de H. Löwe), Stuttgart, 1982, p. 819/865 y especialmente "Die ethischen Implikationen der Auseinandersetzung zwischen Hraban und Gottschalk um die Prädestinationslehre", en: Archiv für Geschichte der Philosophie, 68 (1986), p. 153/173. 
taba la recepción del bautismo para ser considerado predestinado por Dios a la salvación. ${ }^{9}$ Dado que para esa doctrina las buenas obras eran innecesarias para tener la certeza de la salvación, Godescalco consideró que ella tenía tres consecuencias nefastas: 1) fomentaba el indiferentismo moral; 2) exponía a la Iglesia a convertirse - después del bautismo - en administradora innecesaria de un aparato sacramental conducente a una salvación ya garantizada por el bautismo; 3) transformaba al Imperio en custodio innecesario de la también innecesaria Iglesia.

Pero además de responder a esa doctrina, Godescalco tambien queria llenar los vacíos de la teoría de la predestinación sostenida por la Iglesia de la época. Según esta teoría, la omniscientia divina previó el pecado de Adán y predeterminó que todo hombre que como consecuencia de ese pecado se presentara en el Juicio Final caído en el mal, fuera castigado con la muerte eterna en el juicio de réprobos. Pero Dios tambien es misericordioso y prefiere que los hombres no padezcan esa pena. Por ello, tambien predeterminó que los hombres tuvieran la posibilidad de la salvación. Así introdujo en el mundo los medios de salvación para que el hombre, usando su libre arbitrio, tenga la posibilidad de determinar, él mismo, su propio destino después de la muerte. De ese modo, la misericordia de Dios abrió la posibilidad de que, lo que hubiera sido la necesidad de la eterna condena consecuente a la justicia aplicada por Dios a la humanidad caída en el pecado, se transforme en posibilidad de salvación. Como consecuencia de ello, Dios predeterminó que todo hombre que haciendo uso de esos medios de salvación puede liberarse de caer en el mal, no sea castigado como réprobo, sino que sea considerado un electus y que, como tal, sea premiado en el juicio de elegidos.

En esta doctrina Dios no ejerce actos de predeterminación individual, sino actos de predeterminación general cuya forma proposicional sería: "todos los que no hagan uso de los medios de salvación se condenan", "todos los que hagan uso de esos medios se salvan". Estos actos son generales, actúan como principios y aseguran la posibilidad de quebrar la necesidad de la condena si se utilizan los medios introducidos por Dios para ello. Pero esta doctrina era insuficiente para explicar la causa de la circunstancia histórica de que la posibilidad de revertir las consecuencias de la caída se verificara solo en algunos casos y no en otros. En otros términos, si los medios de salvación fueron puestos a disposición de todos, no se explicaba porqué no todos accedieron a ellos. La doctrina de la Iglesia quería asegurar una posibilidad poniendo los medios de salvación a disposición de toda la humanidad, pero puesto que esos medios no llegan a todos, no toda la necesidad se trans-

9 Algunos datos de la época testimonian que, efectivamente, existía algún problema de comprensión en relación con los efectos del bautismo. En el 1811 Carlomagno envia una carta a todos los obispos del Imperio pidiendo información acerca de la interpretación que se daba al rito bautismal ́véase la Epistola Karoliad Archiepiscopos regni Francorum de ceremoniis Baptismi, en F. Walter, Corpus Iuris Germanici Antiqui, Tomus II, Berolini, 1824, p. 244. A ello se debe agregar que parece haber estado en duda el significado de la expresión "accipe sal sapientiae propitiatus in vitam aeternam". El significado del propitiatus no era claro teológicamente; se trataba de una expresión heredada desde la época de San Agustin, pero que en la época de Godescalco desaparece del rito. El tercer dato, y el más importante, es la ya mencionada opinión de que el bautismo basta para alcanzar la salvación; esa opinión fue combatida en el 850 por la decisión de un concilio, lo que muestra que ella contaba con numerosos seguidores que justificaban una condenación (cfr. Schrimpf, "Der Beitrag Johannes Scottus Eriugena...", cit., p. 822 ss.). 
formaba en posibilidad; la posibilidad se aseguraba solo en relación con los que reciben la fé; los que no reciben esa posibilidad concreta de la fé no tenían la posibilidad de salvarse, sino la necesidad de condenarse como consecuencia del pecado de Adán. Por otra parte, Dios previó quién estaría entre los electi y quien entre los reprobi; previéndolo, abrió la posibilidad general y de principio, dada por los medios de salvación. Pero esa posibilidad no les llegó históricamente a todos, sino a algunos: si Dios conoce de antemano el destino eterno de cada hombre, pero no puso a disposición de todos los hombres el aparato de salvación, ¿acaso ese destino de salvación y de condena no está fijado desde siempre?

Junto con su respuesta a esta pregunta, Godescalco procuró sustituir la afirmación de que el bautismo basta para poder ser considerado elegido por otra que dice que solo el bautizado que obra bien es un elegido, pues solo las buenas obras - y no solo el bautismo - constituyen un signo de elección. El propósito de Godescalco fue formular una teoria que fomentara la realización de buenas obras. Así afirma que el Dios misericordioso, antes de la creación del mundo,exceptuó a algunos hombres del castigo eterno sin que esos hombres nada hicieran para merecer esa excepción. Los que quedaron excluídos de ese acto se condenaron; pero no los condenó Dios, sino que se condenaron como consecuencia del pecado adánico que afectaba a toda la humanidad. Mientras que la causa de que algunos se salven reside en la misericordia divina, la causa de que los condenados se condenen nada tiene que ver con ese acto de elección divina, sino con el pecado de Adán. El hecho de que Dios, en su predeterminación, haya escogido a algunos, no es un hecho predeterminante de que los otros se condenen. Solo la Iglesia de los electi constituye el cuerpo de Cristo. Los bautizados que no se encuentran entre los elegidos constituyen, junto con los paganos, el cuerpo del Anticristo. ${ }^{10}$ Como lo podremos percibir al referirnos a Wyclif, esta afirmación tiene consecuencias políticas en el siglo XIV.

Godescalco apoya su teoria de la predestinación en una ética-antropológica según la cual las acciones humanas, o bien son realización o bien son represión del instinto. En el caso de la realización del instinto, Godescalco explica el obrar humano empricamente como efectivización del instinto de acuerdo a la ley natural que se verifica en el hombre. Estas acciones se explican por la concupiscencia consecuente al pecado de Adán y muestran que la naturaleza humana está caída en el mal al mismo tiempo que muestran que el hombre es un réprobo, pues el que obra se revela en ellas como objeto del instinto. En el caso de la represión del instinto, esta represión es una omisión del instinto, una reacción a un determinado impulso instintivo. Empiricamente, esta represión del instinto solo puede constatarse en su desarrollo acorde a la ley natural mientras ella sucede, pero su explicación última o su comienzo no puede ser explicado mediante causas empíricas; por ello a falta de explicación empírica satisfactoria, Godescalco explica esa represión como causada por Dios en el hombre: las represiones del instinto son acciones que

10 "...Et ut apparet et lucet ac claret in plenitudine detentio est Christi ac per hoc quia sola electa ecclesia est corpus eius et plenitudo eius, in ipsa sola quae corpus est Christi manet ad salutem et proficit ad remedium in vitam aeternam corpus et sanguis Christi, non in membris diaboli et corpore Antichristi" (cf. D. C. Lambot, Oeuvres Théologiques et Grammaticales de Godescalc d'Orbais, Louvain, 1945, p. 189, 10-15). 
revelan a un hombre como electus porque Dios obra en él. Ese "evitar" muestra que el hombre en el que Dios evita la realización del instinto se cuenta entre los elegidos. Dios ejerce un único acto, el de elección de los electi, pero ese acto divide a los hombres automáticamente en dos grupos, elegidos y réprobos. Godescalco llama a ese acto gemina praedestinatio. ${ }^{11}$ Debe saberse elegido aquél que, además de estar bautizado, realiza buenas obras: obra bien porque, reprimiendo el instinto, es Dios el que obra en él.

\section{3 - Rhabano Mauro combate a Godescalco}

Aunque Godescalco no sostuvo la idea de una predestinación a la condena, su doctrina fue interpretada como doble predestinación. En rigor Godescalco solo había afirmado que Dios solo está presente en la predestinación al bien. En esa predestinación a la salvación estaba implícita, aunque Godescalco no hace referencia a ello, una predestinación a la condena de los que no fueron elegidos. El obispo de Maguncia Rhabano Mauro concluyó, a partir de esa predestinación doble a la salvación y a la condena, que Dios, predestinando a unos al bien, predestina a los otros al mal, y que por ello Dios predestina al bien y al mal empujando a unos a hacer el bien y a otros a hacer el mal. Así, Dios predestina al pecado. Esta doctrina fue juzgada como destructiva de la responsabilidad moral, que era el fundamento de la vida moral de la sociedad carolingia. Si estamos predestinados a la salvación o a la condena, el carácter misionario del Imperio, su función de protector de la Iglesia y la función de la Iglesia como acompañante del cristiano y administradora de los medios de salvación carecían de sentido. Combatiendo a Godescalco, la cultura carolingia se defendía de su propia destrucción.

Rhabano Mauro, obispo de Maguncia, conoce hacia 840 la doctrina de Godescalco indirectamente a través de algunos de sus seguidores. Para mostrar los errores de Godescalco, formula la siguiente interpretación de la teoría de la predestinación: ${ }^{12}$ Dios previó el pecado que cometería la humanidad en Adán y previó que las consecuencias del pecado caerian sobre toda la humanidad que, con ese primer pecado, se transformaría en eternamente punible; pero Dios es tambien misericordioso y predeterminó que la humanidad tuviera la posibilidad de salvarse; para ello puso a su disposición los medios de salvación; si además de bautizarse, el hombre realiza buenas obras, será recompensado con la vida eterna; pero si no está bautizado o si, apesar del bautismo, realiza malas obras, será condenado. Es obvio que Dios sabe de antemano (prescientia) quién tendrá la Fé y quién realizará buenas obras. Por ello predeterminó a la vida eterna a los hombres que realizarían buenas obras. As lo hizo porque, en su prescientia, sabía que realizarían buenas obras; pero no los predeterminó a hacer buenas obras. Del mismo modo Dios tambien sabe de antemano quién no realizará buenas obras, sea porque no tiene la Fé, sea porque a pesar de tenerla no la utiliza. A estos hombres no los predeterminó de antemano a realizar malas obras. Las malas obras de estos hombres no son el resulta-

11 Esta era una fórmula que ya había sido usada por Isidoro de Sevilla, que la había explicado asi: "Hay una doble predestinación, la de los elegidos a la paz eterna, y la de los condenados a la muerten (Sententiae, II 6,1 en: Migne, Patrologia Latina, 83, col. 606).

12

De praedestinatione, en: Migne, Patrologia Latina, tomo 112, col. 1531-1553. 
do de la predeterminación divina, sino una consecuencia del pecado original. Dios solo predeterminó de antemano que los hombres que realicen malas obras sean castigados con la muerte eterna. Por ello escribe:

"La predeterminación no es otra cosa que el regalo de la vida (eterna), no la condenación a la caida". ${ }^{13}$

El planteo de Rhabano abria dos problemas: ¿porqué se le concede a este hombre la gracia del bautismo, pero no a este otro hombre? Y ¿porqué este bautizado está en condiciones de realizar buenas obras hasta el fin de sus días, y no está en condiciones de lo mismo este otro bautizado? De la doctrina de Rhabano se sigue que Dios, en el Juicio Final, castiga merecidamente al bautizado que ha vivido inmoralmente por sus propias malas obras, pues a pesar de haber accedido al bautismo obró mal; pero tambien castiga al no bautizado que no pudo evitar obrar mal porque, al no haber accedido al bautismo, no pudo neutralizar las consecuencias del pecado de Adán. La doctrina de la predestinación de Rhabano tenia la función de mover al incrédulo a bautizarse transformándose así en sujeto moral responsable, y mover al bautizado a obrar determinando él mismo su propio destino. El bautismo produce una decisiva transformación del status ontológico del hombre, pues recién el bautizado es capaz de autodeterminación. Su destino eterno después de su muerte corporal yace en sus manos. En cambio, según la interpretación que hace Rhabano de la doctrina de la predestinación de Godescalco, éste arranca de manos del hombre esa posibilidad de autodeterminación y la pone en manos de Dios. Según Rhabano, Godescalco sostiene:

"que ningún hombre predestinado a la vida, puede entrar en la muerte, y que ningún hombre predestinado a la muerte puede alcanzar la vida". ${ }^{14}$

Rhabano formula esta proposición que atribuye a Godescalco prospectivamente, desde el presente y mirando hacia el Juicio Final, la interpreta de modo fatalista y la acusa de fomentar el indiferentismo, pues esa proposición me declara predestinado de antemano, sin posibilidad de alterar esa predestinación. Rhabano agrega que si quiero tener un signo que me permita saber ahora si estaré entre los réprobos o entre los elegidos, antes debo tener en cuenta que antes de la creación del mundo, mi destino ya estaba fijado. Por ello Rhabano concluye que, de acuerdo a la doctrina de Godescalco, carece de sentido que me esfuerce por encontrar ese signo y por llevar una vida moral, porque si mi destino está fijado de antemano, por más que me preocupe de llevar una vida moral, viviré de acuerdo a lo que Dios haya predestinado para mi. Rhabano concluye que la consecuencia de la teoria de Godescalco sería:

"¿Para qué necesito preocuparme de mi descanso y de mi salvación? Pues si estoy predestinado por Dios a la vida eterna, llegaré a ella lo quiera o no lo quiera. Y si no estoy predestinado a ella ¿de qué me sirve realizar buenas obras y actuar virtuosamente si no tendré el premio de la vida eterna? ${ }^{15}$

\footnotetext{
13 Ibid., col. 1540.

14 Cfr. Schrimpf, "Der Beitrag des Johannes Scottus...", cit., p. 825.

15 Ibid., p. 826.
} 
Para Godescalco, en cambio, esa proposición formulada en este momento no produce los efectos negativos que denuncia Rhabano, sino que me coloca en una situación ambigua: por una parte me da la certeza absoluta de que estoy predestinado o a la salvación o al castigo; por la otra me coloca en la incertidumbre respecto de si me encuentro entre los electi o entre los reprobi. Se trata, pues, de una predestinación indeterminada, pues sé que estoy predestinado, pero no puedo saber con certeza, a qué estoy predestinado. Por ello, ante la incertidumbre, que fomenta todo lo contrario que el indiferentismo, para transformar esa incertidumbre en certeza y asegurarme desde ahora un lugar entre los elegidos, debo llevar una vida moral. Mi incertidumbre me forzará a conseguir la seguridad de mi salvación haciendo buenas obras, pues éstas son un signo de predestinación a la salvación. Para Godescalco, en el estado de incertidumbre presente acerca de mi destino final, siempre existirá el propósito de llevar una vida moral para convertir la incertidumbre en certeza de salvación. Rhabano malentiende a Godescalco, pues pasa por alto que la desesperación a que me conduce la incertidumbre es transitoria, ya que ella desaparece tan pronto como logro llevar una vida moral. La desesperación sólo será definitiva si no llevo esa vida moral.

Godescalco admitiria que esa proposición podría tener consecuencias nefastas y podría fomentar el indiferentismo solo si ella fuera formulada en un momento en que yo pudiera saber con certeza que me salvo o que me condeno. Pero esa certeza solo la puedo tener en el Juicio Final, es decir cuando ya es tarde para que la proposición pueda fomentar el indiferentismo, porque se trata del momento en que seré juzgado, y en ese momento resultará vano que me abandone o no al indiferentismo; lo haga o no, el Juicio será tardío para ello, ya que en ese preciso momento seré juzgado y por ello careceré de toda posibilidad de obrar moral o amoralmente.

Si formulo la proposición en el momento del Juicio y mirando hacia atrás, desde el Juicio Final hacia el presente, si el que la formula se encuentra entre los elegidos y mira hacia atrás, comprenderá que pudo llevar una vida moral hasta el fin de sus días porque Dios actuó en él. Inversamente, quien en el Juicio Final se encuentre entre los condenados y mira hacia atrás, comprenderá que no pudo comportarse moralmente porque Dios no actuó en él. Solo en el momento del Juicio tiene plena validez la proposición "quien está predestinado a la vida no puede condenarse y viceversa". Pero en el momento del Juicio las consecuencias de la proposición para mi conducta son nulas.

\section{4 - Godescalco es condenado en Alemania y en Francia}

Hacia 848 Godescalco está en Maguncia donde Rhabano era obispo. En un sinodo convocado para examinar la doctrina de Godescalco, Rhabano le pregunta si de su interpretación puede sacarse la siguiente conclusión:

"La predeterminación divina consiste en el bien y en el mal. Por ello hay en este mundo hombres que no pueden desistir del error y del pecado, pues la predeterminación divina los compele a caer en la muerte; como si Dios, desde el comienzo, los hubiera creado incorregibles, destinados a la caida y sometidos a la pena", ${ }^{16}$

16 Ibid., p. 828 . 
Godescalco parece haber respondido afirmativamente a la pregunta de Rhabano, que de inmediato lo condena por hereje. En presencia de Luis el Pío y siguiendo la regla de San Benito, Godescalco es azotado, sus escritos lanzados al fuego y Godescalco es enviado al obispo de Reims, Hincmar, para que lo encierre en un monasterio de su diócesis. Es el momento en que Hincmar recibe, según Cappuyns, "un regalo inesperado" acompañado de una carta de Rhabano que dice:

\begin{abstract}
"Que vuestra caridad sepa que un monje gyrovacus de nombre Godescalco, que dice haber sido ordenado en vuestra diócesis, ha llegado desde Italia difundiendo una doctrina perniciosa sobre la predestinación divina que induce al pueblo al error. Él pretende que la predestinación de Dios se ejerce tanto en el mal como en el bien, y que en este mundo hay hombres que no pueden corregirse del error y del pecado porque la predestinación de Dios los constriñe a ello... Habiéndolo oído exponer su opinión recientemente en el sinodo de Maguncia y habiéndolo hallado incorregible, hemos decidido, bajo mandato y anuencia del rey Luis el Pio, enviaroslo para que lo encerriés en vuestra diócesis de la que ha escapado irregularmente y para que le impidáis enseñar su error". ${ }^{17}$
\end{abstract}

Un cronista de la época relata con satisfacción, que habiendo regresado Godescalco a Francia, la integridad de la Iglesia en Germania permaneció inalterada (inlesus permansit status aecclesiae).$^{18}$ Esta referencia al modo como la doctrina de Godescalco afectaba a la Iglesia junto con la alusión de Rhabano al modo como esta doctrina inducía al pueblo al error no son superfluas. En esos años Rhabano era el único sobreviviente de los discípulos de Alcuíno. Por ese motivo Hincmar considera a Rhabano como la autoridad en materia teológica. Por ello acepta la interpretación que hace Rhabano de la doctrina de Godescalco.

Hincmar trató de disuadir a Godescalco de que abandonara la fórmula gemina praedestinatio, pero sin éxito. En el 849 lo hace condenar en el sinodo de Quierzy en presencia de Carlos el Calvo. Un pasaje de la sentencia de condenación se agrega a las referencias anteriores que aluden al modo como las consecuencias prácticas de la doctrina de Godescalco llegaban a afectar el orden político del imperio carolingio:

"... contrariamente a tu vocación y a tu profesión de monje has alterado el orden eclesiástico y civil en menosprecio del derecho de la Iglesia". ${ }^{19}$

La prohibición de escribir con que el sínodo sancionaba a Godescalco no fue observada por éste. Godescalco volvió a actuar cuando atacó una carta episcopal de Hincmar (Ad simplices) sobre el problema de la predestinación. Ello movió a Hincmar y al rey Carlos a procurar demostrar el carácter herético de la doctrina de Godescalco por medios más eruditos que la simple condena eclesiástica. Así pidieron su parecer a distintos intelectuales de la época que, sin embargo, encontraron la interpretación de Godescalco como concordante con el pensamiento de Agustín, y por ello irreprochable. Es aquí donde entra a jugar su papel Escoto Erígena, a quien se le solicita que refute científicamente la doctrina de Godescalco y que demuestre que, según la doctrina de la predestinación de la Iglesia, el hombre debe ser concebido como un sujeto moral capaz de autodeterminarse.

17 Cfr. Maieul Cappuyns, Jean Scot Érigène. Sa vie, son oeuvre, sa pensée, Bruxelles, 1969, p. 102s.

18 Ibid., p. 103, nota 2.

19 Ibid., p. 104. 


\section{5 - Conclusión: las causas de la condenación de Godescalco}

La casi simultánea condenación de la doctrina de Godescalco en la parte oriental y en la parte occidental del Imperio carolingio y la presencia en los dos actos de condenación de las más altas autoridades de la Iglesia y de los respectivos reyes Luis el Pío y Carlos el Calvo muestran el empeño de la autoridad eclesiástica y civil en acabar con una doctrina de la predestinación que hacía peligrar el fundamento de la moralidad de la sociedad carolingia. Ese fundamento amenazado afirmaba que el bautizado puede obrar libre y responsablemente y que, en consecuencia, él mismo determina su destino mediante su conducta en ésta vida. Si se imponía la doctrina que se atribuía a Godescalco, la Iglesia seguía siendo necesaria, pero el permanente acompañamiento de la Iglesia durante la vida de cada fiel para administrar los restantes sacramentos resultaría superflua. La función mediadora de la Iglesia entre Dios y el bautizado ya no sería necesaria. De eșe modo, la gran estructura de la Iglesia carolingia y la fuerza del gobernante temporal como custodio de la Iglesia se revelaban como carentes de sentido. La gran estructura eclesiástica perdia su posición como autoridad moral y religiosa.

La versión de la doctrina de Godescalco que le llegó a Escoto es tambien la de la gemina praedestinatio equivalente dos actos divinos de predeterminación. La tarea que se le encomienda de Escoto es volver a recolocar la causa de la condena en Adán, pues Dios es el sumo Bien y no puede querer o causar el mal; solo el mal uso de la libertad por parte del hombre puede causar el mal. Ello muestra que en última instancia, el conflicto acerca de la predestinación se desató a causa de un error subjetivo: el error de la interpretación de Rhabano. Pero la conducta de Rhabano e Hincmar posterior a ese error subjetivo estaba fundada en un temor bien objetivo: que Godescalco pusiera en peligro las bases del imperium christianum, que se derrumbara el gran aparato político, moral y eclesiástico que actuaba como apoyo de la vida cristiana y que, como tal se legítimaba. Por ello, en el fondo de esta polémica se jugaba no solo la predestinación y la libertad, sino las consecuencias morales y politicas de la falta de libertad. Dentro de este contexto, Escoto actuó como el intelectual que debe recuperar la legitimidad del orden eclesiástico.

\section{6 - Contexto histórico de John Wyclif}

La significación histórica del programa político de Wyclif se comprende si se lo interpreta como el intento de un scholar inglés de destruir la teoría de la plenitudo potestatis papal con argumentos de la misma naturaleza teológica que los que el Papado había utilizado para construir esa misma teoría. Godescalco no había tenido detrás de sí los conflictos entre el poder espiritual y el poder temporal que conoció Wyclif al fin del medioevo. ${ }^{20}$ En los cinco siglos que separaron a Wyclif de Godescalco se habia desarrollado una doctrina de la plenitudo potestatis como sistema teórico coherente elaborado sobre sólidas bases teológicas. La respuesta de Wyclif a la teología política del Papado muestra su distancia del naturalismo político inaugurado un siglo antes por la introducción en Occidente de la Politica de

20 Para la vida de Wyclif puede consultarse la obra de H. B. Workman, John Wyclif. A study of the english medieval Church, 2 volúmenes, Oxford, 1926. 
Aristóteles. En efecto, Wyclif no recurre a argumentos filosóficos, como lo hicieron los tratados de filosofía política inspirados en las obras aristotélicas, sino que se opone teológicamente al pensamiento papal. Su teología política actúa como contrateoría de la teología política formulada en la bula Unam Sanctam de Bonifacio VIII. El mundo de Wyclif es la Inglaterra de la segunda mitad del siglo XIV, la Inglaterra de Chaucer que, según la descripción de Trevelyan, comienza a surgir "como nación distinta" y que deja de ser "mera prolongación de la Europa franco-latina". Es la Inglaterra en la que por primera vez "se mezcla lo moderno con lo medieval". ${ }^{21}$ Uno de los testimonios a que recurre Trevelyan para describir la situación de la Inglaterra de esos años es el poema Canterbury Tales de Chaucer, cuyo Prólogo presenta algunos de los personajes de la escena social y religiosa que le toca vivir a Wyclif. Chaucer describe situaciones y pone en boca de algunos de esos personajes versos que reflejan la visión inglesa, popular y no conformista, de la Iglesia de la baja Edad Media.Así el fraile es la sintesis de la malicia de las cuatro órdenes: ${ }^{22}$ Carmelitas, Agustinos, Iacobitas (= dominicos) y Minoritas - a quienes los seguidores de Wyclif, utilizando la letra inicial del nombre de cada una de esas órdenes, llamaban "hijos de CAIM" ${ }^{23} \mathrm{El}$ párroco pobre, en cambio, es el paradigma del cristiano $0^{24}$ y, según las investigaciones de los historiadores y de los críticos literarios, representa la figura de un miembro de la lollardy, es decir del movimiento de protesta que se habia formado como consecuencia de la intensa prédica de reforma religiosa llevada adelante por Wyclif. ${ }^{25}$

Esta versión de la disconformidad popular inglesa que presenta Chaucer repite, en la literatura, la misma visión que presenta la teología de Wyclif. Su ataque a las órdenes religiosas, su prédica de un cristianismo primitivo y escriturario y su promoción de una traducción inglesa de la Biblia, accesible directamente al pueblo y sin necesidad de un clero mediador entre el texto y su destinatario son - para utilizar palabras del mismo Wyclif - un intento de "restitutio Ecclesiae ad statum quem Christus docuit" ${ }^{26}$ y constituyen un presagio de su éxito posterior y de los futuros acontecimientos políticos y religiosos propios del movimiento de reforma que tuvo lugar en el mundo anglosajón.

La teología política de Wyclif está organizada alrededor de dos ideas. La primera es la idea de "estado de gracia"; éste fundamenta la posibilidad del dominium que, a su vez, comprende la possessio o propiedad y la potestas o gobierno y/o jurisdicción. La segunda idea es la de divina praedestinatio, sobre la cual Wyclif fundamenta su teoría de la Ecclesia.

21 G. M. Trevelyan, Histonia social de Inglaterra, Fondo de Cultura Económica, México, 1946, esp. p. 19.

22

"iba en el grupo un fraile mendicante... No habia, ni aún juntando las cuatro órdenes, fraile que le igualase en saber malicias" (cfr. G. Chaucer, Canterbury Tales, with an Introduction, notes and a Glossary by John Matthews Manly, NewYork, 1928, p. 154).

23

24

25

26

Ibid., p. 511.

"Acompañábanos un pobre párroco, rico en santos pensamientos y obras..."(cfr. ibid., p. 161).

"The Person evidently represents Chaucer's conception of the ideal priest. One of the pilgrims (II, 1173) takes him for a Lollard..." (crr. ibid., p. 528).

Tractatus de civili dominio (ed. R. L. Poole), Londres, 1885, II, 153. 


\section{7 - Teoría del "dominium" en Wyclif}

Wyclif presenta su teoría del dominium con validez para toda organización social humana. Considerada en sí misma, la teoría del dominium no parece tener que ver directamente con la Iglesia. Su objetivo primario es la fundamentación del gobierno (potestas) y de la propiedad (possessio) en general. Pero como la Iglesia es un grupo social, la teoría del dominium es aplicable tambien a ella, lo que permite a Wyclif neutralizar la potestas iurisdictionis eclesiástica e impugnar la facultad del clero de tener propiedad.

Ya antes de Wyclif, Richard Fitzralph había formulado una teoría del dominium. En ella afirmaba que Dios es supremo señor de todas las cosas y que el hombre - creado como imago Dei y colocado por encima de todas las cosas que le son inferiores - recibe de Dios la facultad del dominium. Siguiendo a Fitzralph, Wyclif traslada los fundamentos del dominium del derecho humano a la gracia divina y formula una teoría negativa del dominium, según la cual sin gracia no es posible el dominium. ${ }^{27}$ Es verdad que el pecador puede poseer, pero se trata de una posesión puramente fáctica, de hecho y solo "natural"; desde el punto de vista evangélico solo el justo posee legtimamente. ${ }^{28}$

Pero en Wyclif la doctrina de la recepción humana del dominium divino asume un carácter particular. En primer lugar solo Dios posee el dominium por excelencia y de modo directo; para entregarlo a los señores temporales, no utiliza intermediarios, sean éstos las instituciones eclesiásticas o el clero. Así Wyclif excluye del Papado toda potestas in temporalibus, directa o indirecta. En segundo lugar, para Wyclif el dominium divino tiene caracteres marcadamente feudales: ${ }^{29}$ Dios, como señor, establece las condiciones de su pacto con el hombre, y éste debe fidelidad a Dios. El hombre ratifica el pacto mientras se mantiene en estado de gracia, pero lo rompe si cae en pecado mortal. Así, la conservación del dominium depende totalmente del status de gracia o de pecado del recipiendiario ${ }^{30}$ La teoria del dominium está apoyada en esa iniciativa divina que, como una especie de flechazo, introduce la potestas y la possessio en la historia, sin ninguna mediación eclesiástica.

A partir de estos presupuestos, Wyclif saca dos consecuencias de teoremática apodicticidad referidas al dominium eclesiástico. En primer lugar, el derecho al dominium es excluído de las manos de los pecadores ${ }^{31}$ y limitado a la comunidad de los justos. Esta communitas iustorum posee en común los bienes cedidos por

27 La teoría negativa del dominium fundado en la gracia, sostenida por Fitzralph y Wyclif, es la que critica Francisco de Vitoria en sus Relectiones theologicae. Véase sobre el tema Robert Schnepf, "Derecho intemacional y soberanía en Francisco de Vitoria (Sobre la forma de la argumentación en las Relectiones theologicae)", en Patristica et Mediaevalia, vol. XIII (1992), esp. p. 85/106, esp. p. 92ss.

Tractatus de civili dominio, I, cap. 7.

29 "... si según el derecho feudal ese dominio puede perderse en virtud de la ruptura del juramento de fidelidad, el derecho de dominio de origen divino está mucho más amenazado cuando, mediante el pecado, se produce la ruptura del juramento de fidelidad a Dios" (cfr. J. Miethke, Las ideas politicas de la Edad Media, Buenos Aires, 1993, p.170). Sobre la mentalidad feudal presente en la teoría del dominium de Wyclif véanse las interesantes referencias de Ch. E. Mallet, A History of the University of Oxford, vol. I, London, 1924, p. 227ss.

De Dominio Divino Libri Tres (ed. R. L. Poole), Londres, 1890, p. 213ss.

31 Ibid., p. 33. 
Dios. ${ }^{32}$ Los prelados de la Iglesia, a quienes se les concedió un dominium espiritual, no terreno, deberían darse por satisfechos con alimento y vestido. ${ }^{33}$ Pero desde Constantino, esa Iglesia cayó en la corrupción y en pecado mortal por no haber respetado el mandato evangélico de pobreza. Así los sacerdotes se convirtieron en sacerdotes caesarei.

Pero Wyclif excluye a la Iglesia del ámbito del dominium por principio, y no solo en virtud de esa situación contingente consistente en el pecado de la Iglesia de Aviñón. El dominium conferido por Dios a la ecclesia solo es espiritual y no abarca ni possessio ni potestas; por ello el clero no puede ser señor, ${ }^{34}$ es decir, no puede tener dominium. De allí que no sean los hombres de la Iglesia los que conceden o transmiten el dominium. Solo el señor temporal es vicario y administrador del poder y de los bienes de Dios. ${ }^{35}$ Más aún, en el De officio regis, Wyclif afirma que a ese vicario temporal no se le puede oponer resistencia. El pecado solo invalida la autoridad de los eclesiásticos, no la del poder temporal. Con ello, Wyclif impugna la cesión del dominium por parte del poder eclesiástico, pero no por parte del poder real.

De esta segunda consecuencia puede colegirse fácilmente que Wyclif es conservador en relación con el poder temporal, pero no en relación con la Iglesia. Administra con discrecionalidad el principio de la gracia como condición del dominium según sea el poder temporal o el espiritual su ámbito de aplicación; a ello agrega que si los eclesiásticos no están en gracia, no solo no son justos posesores de propiedad, sino que inclusive pueden ser privados de ella por el poder secular). ${ }^{36}$ El sacerdote que muestra no estar en estado de gracia puede ser privado de sus beneficios. Es verdad que, en principio, esa medida disciplinaria corresponde, ante todo a la Iglesia. Pero como Wyclif considera que la Iglesia de la época está corrompida, esa función disciplinaria la debe cumplir el poder temporal que tiene el deber divino de privar a los sacerdotes de sus posesiones, pues es el poder temporal el que tiene la responsabilidad de las cosas temporales. Y por último afirma que está prohibido el uso de la fuerza contra el poder civil existente, aún cuando se trate de tiranos explícitos. ${ }^{37}$ Puede concluirse, pues, que si bien es verdad que el principio de la gracia, entendido como principio general "vale tanto para los prelados eclesiásticos como para los gobernantes temporales, Wyclif tendía a aplicarlo especialmente a los prelados". ${ }^{38}$

\section{8 - La teoría de la "Ecclesia" de Wyclif}

Mientras con su teoria del dominium Wyclif apunta a reducir el poder temporal de la Iglesia, tanto en la variante de la potestas como en la de la possessio, con su teoría de la Ecclesia apunta a aniquilar el poder espiritual pretendido por la Iglesia

\footnotetext{
32 Tbid., I, 30.

Tractatus de civili dominio, I, cap. 2.

Ibid., 35.

Ibid., I, cap. 3.

Ibid., I, cap. 37; II, cap. XII.

Ibid., I, cap. 28.

Crr. Miethke, op. cit., p.172.
} 
institucional y a desarticular el poder de la Iglesia como mediadora y administradora de los instrumentos de salvación. Para ello debe demostrar que esa Iglesia institucional no es la verdadera Ecclesia, ya que si lo fuera, tendría un poder espiritual - no de dominium - que, en rigor, solo corresponde a la Iglesia eterna. En su tratado De Ecclesia Wyclif define la Iglesia como universitas fidelium praedestinatorum..$^{39}$ La idea de praedestinatio es fundamental para deconstruir el poder de la Iglesia institucional y para reconstruir la figura escatológica de una Ecclesia eterna. Por ello Wyclif distingue entre preconocidos (presciti) y predestinados (praedestinati):

"Hay pues algunos que son predestinados, es decir los que están ordenados a la gloria después de los trabajos de esta vida, otros son preconocidos, es decir los que están ordenados a la pena perpetua después de esta vida miserable" ${ }^{40}$

El requisito de la divina praedestinatio, como rasgo constitutivo y conditio sine qua non de la definición de la Ecclesia, actúa con efectos fuertemente restrictivos y limitativos al momento de la caracterización de la Ecclesia y tiene graves repercusiones sobre la constitución histórica de la Iglesia institucional. En efecto, para formar parte de la verdadera Ecclesia no basta con estar entre los creyentes que se encuentran actualmente en estado de gracia, pues ese estado actual - en última instancia fugaz y sujeto a la mutabilidad - no garantiza la condición de predestinado. El carácter transitorio de la situación de quien se encuentra ahora en estado de gracia hace que el concepto de Ecclesia tampoco sea satisfecho por una agrupación que combine predestinados y fieles en estado actual de gracia. La pertenencia actual al estado de gracia resulta completamente irrelevante al momento de definir la Ecclesia. Del mismo modo, y así como no existen vínculos necesarios entre estado de gracia y la condición de predestinado, tampoco existe ninguna incompatibilidad entre la condición de predestinado y el hecho de que éste se encuentre o no en estado actual de pecado. Por ello tambien resulta totalmente irrelevante para la definición de Ecclesia el hecho de que los predestinados que constituyen esa $E_{C}$ clesia se encuentren en estado actual de pecado. De hecho, la historia de la salvación enseña que fueron pecadores muchos de los predestinados a formar la Ecclesia. En consecuencia, mientras la verdadera Ecclesia solo está formada por los predestinados desde toda la eternidad a la salvación, independientemente de la situación histórica de gracia o de pecado de esos predestinados, en cambio la Iglesia institucional reúne praesciti y praedestinati. Y puesto que no sabemos ahora quiénes se encuentran entre los praesciti y quiénes entre los praedestinati, la pertenencia actual a la Iglesia institucional de ninguna manera puede actuar ni como garantía de salvación ni como signo de posesión de autoridad de carácter salvifico.

Esta concepción de la Ecclesia tiene tres consecuencias importantes que afectan la naturaleza de la Iglesia institucional.

En primer lugar, la única y verdadera Iglesia es la Iglesia escatológica y eterna de los predestinados. Ese carácter escatológico hace que, aunque hipotéticamente la Iglesia institucional alguna vez pudiera llegar a coincidir con la Iglesia de los pre-

39 De Ecclesia (ed. J. Loserth), Londres, 1886, p. 8 y 408 s.

40 "Et sic sunt aliqui praedestinati, hoc est post laborem ordinati ad gloriam, aliqui presciti, hoc est post vitam miseram ad poenam perpetuam ordinati" (Trialogus, ed. G. Lechler, Oxford, 1869, p. 122). 
destinados - lo que significaría que todos los miembros de la Iglesia institucional son predestinados - de todos modos, puesto que solo podemos conocer esa coincidencia al final de la historia, ella carecerá de todo efecto en la vida histórica. Así, el acceso al conocimiento de la constitución de la Iglesia se verifica en un momento en que ese conocimiento será inútil para tener efectos institucionales en el tiempo.

La limitación del concepto de Ecclesia a la universitas praedestinatorum tiene dos objetivos: introducir una solución de continuidad entre la Iglesia institucional y la salvación y arrancar a la Iglesia institucional todo perfil necesariamente salvífico que justifique su autoridad. Si la Iglesia institucional tiene alguna autoridad, se trata solo de una autoridad de hecho, pero que carece de poder salvífico. Esa autoridad no proviene de una dependencia de la Iglesia institucional respecto de la $E C^{-}$ clesia aeterna, sino del poder civil. Estar in Ecclesia no es lo mismo que ser de Ecclesia. Así, puesto que en última instancia cada praedestinatus perteneciente a la Iglesia eterna (de Ecclesia) debe ser considerado más sacerdote que el sacerdote miembro de la Iglesia institucional (in Ecclesia), esta Iglesia y todo el aparato eclesiástico y clerical que forma parte de ella pierden toda autoridad frente ala Ecclesia eterna.

En segundo lugar, la definición de la Iglesia como universitas fidelium praedestinatorum hace imposible a los hombres acceder actualmente al conocimiento de la constitución de la Iglesia. Solo Dios sabe, desde su infinita omniscientia y desde toda la eternidad, a quien ha predestinado a la vida eterna, mientras que los hombres, que durante su vida histórica ignoran si están predestinados a la salvación, pueden tener un conocimiento escatológico acerca de la Ecclesia recién al final de la historia. Puesto que tanto la constitución de la verdadera Iglesia - definida desde antes de la historia - como la pertenencia a ella, son imposibles de determinar en la historia, la cabeza de la Iglesia no puede ser un hombre acerca del que no sabemos con certeza si pertenece o no a ella. Su única cabeza solo puede ser Cristo. La humana incertidumbre respecto del carácter de praedestinatus o praescitus de los miembros de la Iglesia institucional nos impide considerar a los sacerdotes y al Papa como formando parte de la verdadera Ecclesia

Pero puesto que es posible que un prelado de la Iglesia institucional esté in Ecclesia pero no sea de Ecclesia, y puesto que es posible que los miembros del poder temporal sean de Ecclesia aunque no esten in Ecclesia, la superioridad del poder espiritual pretendido por la Iglesia institucional sobre el poder temporal queda neutralizada, ${ }^{41}$ pues esa superioridad se basa en una pertenencia a la Ecclesia eterna solo pretendida, pero imposible de probar. Esa neutralización se basa en el hecho de que la superioridad de un poder sobre otro solo puede estar apoyada en la absoluta certidumbre de pertenecer a la Ecclesia, es decir en el hecho - incierto para los hombres - de ser de Ecclesia.

41 "Por más que se encuentren actualmente en estado de gracia, ni los prelados ni el Papa saben si en última instancia pertenecen a la Iglesia de los predestinados, es decir a la Iglesia en el sentido estricto del término. A partir de esta concepción, todas las diferencias entre el poder temporal y el espiritual pueden ser consideradas como secundarias..." (cfr. Miethke, op. cit., p. 172; subrayado nuestro). 
En tercer lugar, el decreto de divina praedestinatio que constituye a la verdadera Iglesia tiene lugar en la eternidad de Dios; de alli que la Iglesia no exista desde la Encarnación, sino desde toda la eternidad. Esa Iglesia eterna se reduce a la intención divina contenida en el eterno decreto de predestinación y, considerada en sí misma, carece de toda estructura humano-institucional concreta. ${ }^{42}$ El recurso de Wyclif al decreto divino de predestinación como fundamento de la ecclesia constituye un interesante resultado de la vinculación entre la filosofía teórica del Wyclif de la escuela oxoniense y su teología política. Una de las mayores peculiariedades de la política eclesiástica de Wyclif se origina, precisamente, en su conjunción de una filosofia escolástica de carácter extremadamente realista, proveniente de Thomas Bradwardine, y una teología de carácter absolutamente predestinacionista.

De esa simbiosis entre filosofía y teología surge un decreto divino de predestinación que actúa como sustitutivo de toda conjetura humana referida a la constitución de la Iglesia. Consecuentemente con ello, ese recurso tiende a trasladar ese fundamento a un principio general cuya necesidad y universalidad supere y neutralice toda interpretación de lo real basada en criterios sujetos a la facticidad y a la contingencia. En este sentido, la teoria de la Ecclesia de Wyclif es absolutamente coherente con su posición de realista extremo en la teoría de los universales. La Ecclesia responde una idea divina indestructible, cuyo grado de realidad es la misma que la de las realidades conocidas como universalia ante rem presentes en el intelecto divino. ${ }^{43}$ Por ello, Wyclif escriba en un texto temprano:

"la Iglesia <institucional> no ordena nada...<sino que> hay una causa racional para su estimación, ya que es asi antes de ser establecida por el hombre" ${ }^{44}$

En sintesis, a través de la reducción de la Ecclesia a una simple idea divina la idea de universitas fidelium praedestinatorum - Wyclif logra: (1) quitar la denominación de Ecclesia a la Iglesia institucional, (2) retrotraer el principio de autoridad eclesiástica hacia Cristo en forma excluyente y (3) aniquilar la función mediadora de la autoridad de la jerarquia eclesiástica en todos sus niveles. Con ello, la reducción de la religión al ámbito de la pura interioridad del individuo era casi automática.

\section{9 - Conclusión: la utopía predestinacionista de Wyclif}

De ese modo, lo que, por analogía con el principio metodológico de Ockham podriamos llamar "la navaja de Wyclif", ya no es aplicada por éste a las entidades metafísicas consideradas superfluas, sino a las estructuras de la Iglesia visible consideradas usurpadoras. La "navaja de Wyclif" cumple los mismos objetivos que el principio de "economía metafísica" de Ockham habia cumplido aplicado a las enti-

42 Ibid., p. 74 y 89.

43 "La Escritura viene a ser un modelo divino concebido en la mente de Dios antes de la creación, y antes de que la Escritura se pusiese materialmente por escrito. Al ser una idea divina, cada una de sus palabras era verdad, y cada parte tan autorizada como la otra. El ultrarrealismo condujo finalmente a un fundamentalismo que, en términos filosóficos, puso a la Escritura más allá de toda duda" (M. D. Lambert, La herejía medieval, Taurus, Madrid, 1986, p. 242). 
dades innecesariamente multiplicadas. Pero paradójicamente, a diferencia de Ockham, Wyclif construye y aplica su principio partiendo de bases filosóficas absolutamente ultrarealistas .Distintos son los puntos de partida filosóficos y distinto es tambien el ámbito de aplicación, pero el resultado de la "navaja de Wycliff" es el mismo si lo consideramos encuanto a su objetivo último: aniquilar instituciones cuya existencia carece de fundamento. Esas instituciones son, para Wyclif, las vinculadas a la Iglesia institucional de la época.

Podemos intentar verificar ahora si el vínculo entre la teoría del dominium y la de la Ecclesia se limita solo al carácter teológico (gratia y praedestinatio) de sus fundamentos o si, además, éstos pueden ser retrotraídos hacia un elemento común que permita establecer algún tipo de efectiva relación entre ambas teorías.

Ante todo debe observarse que en ambas teorías la argumentación está articulada siguiendo una estructura alternativa, esto es, de exclusión absoluta cuya forma lógica es "aut-aut". Asi, en relación con el dominium, cuya formulación positiva es "si gratia entonces dominium", la pérdida del estado de gracia implica la automática pérdida del dominium, con lo que la alternativa asume la forma aut peccatum aut dominium. Del mismo modo, en el caso de la Ecclesia, cuya formulación positiva es "si praedestinatus entonces de Ecclesia", la condición de praescitus (= no predestinado) implica estar excluído de la Ecclesia, de allí que en este caso la estructura sea aut praescitus aut de Ecclesia.

Si se tratara ahora de intentar establecer los vínculos que unen la teoría del dominium con la de la Ecclesia, deberá tenerse en cuenta que, en principio, Wyclif presenta ambas teorías como totalmente desvinculadas y aisladas entre sí. La teoría de la gracia y la de la Ecclesia parecen formar parte de un programa cuya función es disminuir gradual y progresivamente ámbitos de ingerencia eclesiástica. Ese aislamiento conduce a paradójicos resultados según los cuales, por una parte, puede verificarse la situación de que un hombre haya sido objeto del decreto de predestinación divina - y que por ello sea de Ecclesia - pero que, apesar de ello, no posea legitimo dominium por encontrarse en pecado. Y por otra parte se puede verificar la situación, tambien paradójica, de un hombre que, por encontrarse en estado de gracia, tenga derecho al dominium, pero que, apesar de ello, no se encuentre entre los predestinados y por ello no pertenezca a la Iglesia. Ello coloca al sistema de Wyclif al borde de la utopía. Pues en efecto, no solo es imposible determinar intrahistóricamente quiénes integra nel circulo de los praedestinati, sino que además, siendo imposible definir el estado de gracia o depecado de los hombres, tambien resulta imposible determinar quiénes pueden ejercer legítimamente el dominium. En rigor según Wyclif, "solo podemos saber cuáles son los principios y las condiciones generales que deben ser satisfechas para ser de Ecclesia y para ejercer legítimamente el dominium", pero, en concreto, nunca podremos saber quiénes constituyen la verdadera Ecclesia y quiénes están en estado de gracia.

En lo que concierne a la constitución de la Ecclesia, la predestinación la carga con un carácter eminentemente prehistórico y escatológico de la que la reduce a una situación similar a la de una gran parábola suprahistórica, tensada entre dos polos extrahistóricos extremos y opuestos: un absoluto antes respecto de la historia, de carácter prehistórico, representado por el decreto de divina predestinación; y un absoluto después respecto de la historia, de carácter posthistórico, repre- 
sentado por el conocimiento escatológico de la constitución de la Ecclesia. Y la utopía continúa en lo que concierne al dominium, en virtud de la imposibilidad de determinar quién se encuentra - y quién no - en estado de gracia, lo que hace imposible verificar, en la historia, quién ejerce legítimamente la potestas y quién posee legítimamente la propiedad. En sintesis, Wyclif solo ofrece criterios generales, pero que en última instancia no permiten pasar del factum al ius, es decir de la Iglesia institucional y del dominium de facto a la Ecclesia aeterna y al dominium de iure.

Hemos visto que, encuanto a su origen, la praedeterminatio es prehistórica, pues nace antes de todo tiempo. Y encuanto a su definición, ella es escatológica o posthistórica, pues el contenido del decreto de predeterminación solo podrá conocerse al final de los tiempos. Sin embargo, este carácter esencialmente y simultáneamente prehistórico y posthistórico o escatológico de la predeterminación, que imposibilita que ella se defina en el tiempo, no significa que ella sea absolutamente ahistórica en el sentido de que carezca de todo efecto en la historia, pues la constitución de la Ecclesia aeterna en el decreto de predeterminación afecta directamente a la Iglesia institucional denunciando la ilegitimidad de sus pretensiones. Pero si bien es verdad que la predeterminación prehistórica tiene influencia directa sobre la historia, en cambio el dominium - que a diferencia de la predeterminación es esencialmente histórico en la medida en que afecta directamente la situación de possessio y potestas de los hombres - carece de todo efecto sobre la Ecclesia praedestinatorum. En este sentido, entendiendo praedeterminatio y dominium como principios fundamentales del sistema teológico-politico de Wyclif, debe concluirse que la fuerza y el poder teóricos del principio "praedeterminatio" es sensiblemente más intenso y de mayor alcance que el del principio "dominium". 